\title{
Perfis de alta resolução da Formação Galho do Miguel com utilização do Georadar no distrito de Guinda/MG
}

Aranha, P.R.A ; Marrismam, R,B, ${ }^{2 *}$; Rocha,L.C ${ }^{3}$. Universidade Federal de Minas Gerais ${ }^{1,2}$;Universidade Federal de São João Del $\mathrm{Rei}^{3}$.

Este texto foi preparado para a apresentação no VII Simpósio Brasileiro de Geofísica, Ouro Preto, 25 a 27 de outubro de 2016. Seu conteúdo foi revisado pelo Comitê Técnico do VII SimBGf, mas não necessariamente representa a opinião da SBGf ou de seus associados. É proibida a reprodução total ou parcial deste material para propósitos comerciais sem prévia autorização da SBGt.

\section{Resumo}

$\mathrm{Na}$ região do distrito de Guinda, Serra do Espinhaço Meridional, Minas Gerais, utilizou-se o método geofísico Georadar a fim de identificar e correlacionar a Formação Galho do Miguel em subsuperfície. Essa Formação é caracterizada por quartzitos puros, finos e esbranquiçados, com estratificações cruzadas e plano paralelas de porte decamétrico bem preservadas, depositadas em ambiente eólico. Os dados geofísicos foram processados e analisados separadamente para cada um dos três perfis obtidos, resultando em imagens da subsuperfície. Nestas imagens foi possível assinar como as estruturas aflorantes aparecem no radargrama como continuidades, interrupções e acunhamentos mostrando a eficácia da ferramenta no estudo destas feições.

\section{Abstract}

In the region of Guinda, district of the southern Espinhaço, Minas Gerais, we used the geophysical Georadars method to identify and correlate the formation Galho do Miguel in the subsurface. This formation it is characterized by pure, thin, whitish quartzite, cross-stratifications and parallel planes of decameters size, preserved, and wind depositional environment. The geophysical data was processed and analyzed separately for each of the two profiles obtained, resulting in images of the subsurface. In these images was possible to see how the hidden structures appear in the radargrama as continuities, interruptions and wedging', showing the effectiveness of the tool in the study of these features.

\section{Introdução}

A área de estudo localiza-se no distrito de Guinda em Diamantina/MG, de coordenadas UTM (23k 633397 7976540). A região denominada Serra do Espinhaço Meridional, esta inserida na Faixa Araçuaí (faixa esta que delimita o Cráton São Francisco a leste). O Espinhaço estende-se por cerca de $300 \mathrm{~km}$ na direção N-S partindo do Quadrilátero Ferrífero até a região de Olhos D'água (Almeida e Abreu 1995). A Serra do Espinhaço é sustentada por uma sucessão de rochas quartzíticas, às quais se confere a denominação estratigráfica homônima de Supergrupo Espinhaço (CPRM, 1974).

A Formação Galho do Miguel, ou Tectonossequência Galho do Miguel (Martins e Neto 1998), é caracterizada por quartzitos puros e finos que constituem mais de $90 \%$ da unidade. Os outros 5 ou $10 \%$ estão representados por quartzitos finos micáceos e por finas intercalações de metargilitos acinzentados ou esverdeados (Knauer, 2007). Os quartzitos da Formação Galho do Miguel possuem estratificações cruzadas e plano paralelas, de portes métricos, bem preservadas. Marcas onduladas também são comuns, e o conjunto de características indica ambiente dominantemente eólico para sua deposição (Dossin et al, 1987). Essa
Formação trata-se de uma unidade Paleoproterozóica, que apresenta afloramentos que impressionam devido à altura que atingem, com elevações chegando à $1.500 \mathrm{~m}$ de altitude.

Um grande número de trabalhos utilizando o método geofísico de Georadar relacionado a sistemas eólicos já foi publicado: Silva et al, 2010, Rocha et al, 2013, Castro et al, 2015, Aranha et al, 2013. Entretanto, em metassedimentos eólicos esse método ainda não havia sido aplicado para identificar estruturas e correlacionar tipos litológicos.

Portanto, a fim de obter estruturas e a correlação com rocha a aflorante, foram adquiridos três perfis com o método geofísico Georadar, próximo a um afloramento da Formação Galho do Miguel (figura 1). Esses três perfis, possuem direção LesteOeste e sua direção precisa se encontra disponível na figura em planta (figura 2a). Após a aquisição dos dados, esses foram processados e interpretados identificando estratificações cruzadas, estratificações cruzadas acanaladas de porte decamétrico, falhas e dobras. Então, realizou-se uma análise relacionando a litologia em subsuperfície com a da rocha aflorante na região. O método geofísico, em geral, se mostrou eficiente se aplicado na direção paralela às estruturas do metassedimento eólico e um pouco desfavorável, mas ainda um pouco perceptível quando aplicado em direções oblíquas.

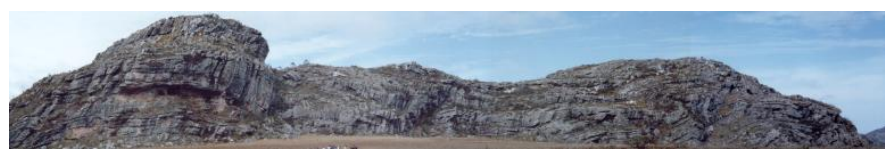

Figura 1 - a) Afloramento da Formação Galho do Miguel próximo onde foram adquiridos os dados.

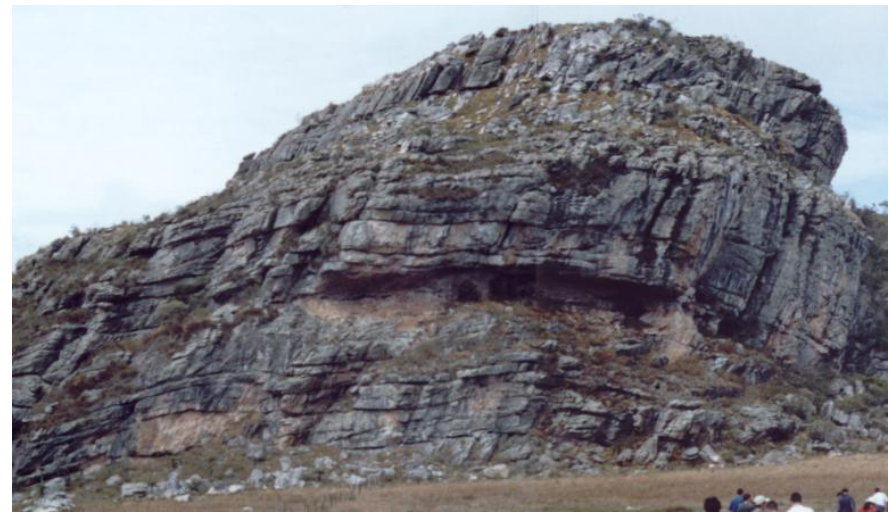

Figura 1 - b) Afloramento da Formação Galho do Miguel destacando as estruturas de estratificação cruzadas acanaladas.

\section{Metodologia/Problema investigado}

O Georadar ou GPR é um método geofísico que emprega ondas eletromagnéticas nas frequências entre 10 e $2000 \mathrm{MHz}$, para localizar estruturas e feições geológicas rasas (Davis e Annan, 1989; Annan, 1992). O método consiste na transmissão de ondas eletromagnéticas repetidamente irradiadas para a subsuperfície através de uma antena transmissora colocada na superfície. O contraste entre as constantes dielétricas dos meios no qual a onda EM se propaga faz com que parte do sinal enviado pela antena transmissora seja refletido 
As ondas refletidas são captadas por outra antena, receptora, também posicionada na superfície. A energia refletida é registrada em função do tempo de chegada da onda na superfície após incidir numa superfície refletora, sendo então amplificada, digitalizada e gravada. (Aranha et al, 2010).

Os dados foram adquiridos com o equipamento Ramac (MalaGeoScience). Foram coletados três perfis de reflexão, tempo versus posição, totalizando cerca de 1010 metros lineares de investigação na configuração "common offset" (Figura 2b). Os perfis foram obtidos utilizando-se as antenas de frequências centrais de $100 \mathrm{MHz}$. A separação entre as antenas transmissora e receptora foi de 1,0 metros e o espaçamento entre cada traço de 0,1 metros.

O processamento dos dados foi realizado com o programa Gradix (Interpex Limited, 1996). As principais etapas utilizadas foram: filtragem dewow (remoção dos ruídos de baixa frequência), correção do tempo zero, filtragem temporal (filtro passa banda), ganhos no tempo (linear e exponencial), filtragem gaussiana, migração e correção topográfica. Além disso, interpretou-se e analisou um perfil de velocidade (CMP), adquirido na linha do perfil 1, para se determinar a profundidade (figura 3).

Após o processamento dos dados, o produto final consistiu em uma imagem de alta resolução da subsuperfície. Então, iniciou-se a identificação e interpretação de estruturas em subsuperfícies, como estratificações cruzadas acanaladas de porte decamétricos, além de falhas e dobras suave.

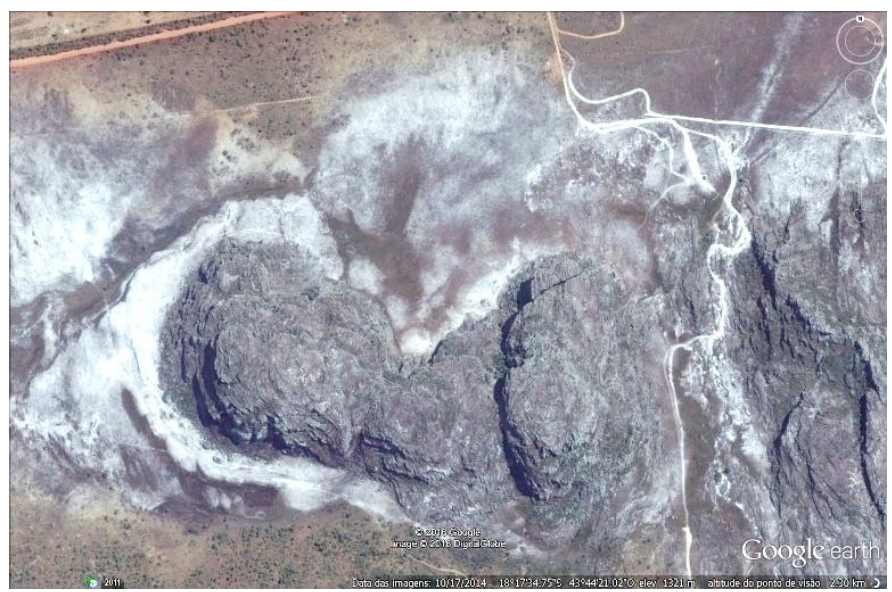

Figura 2 - a) Imagem Google Earth do local de estudos.

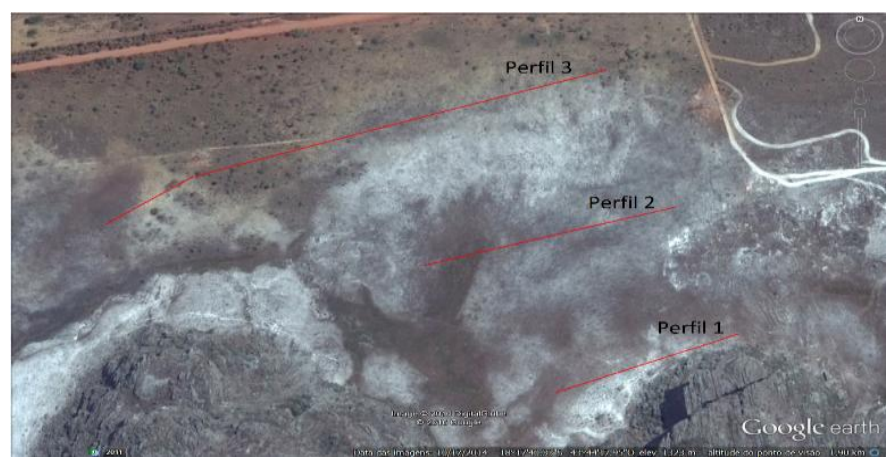

Figura 2 - b) Imagem Google Earth com a disposição dos perfis.

\section{Resultados(500-600)}

O Georadar mostra eficiência no mapeamento da geometria de estruturas, sendo possível evidencia-las em subsuperfície de forma muito bem destacada. No radargrama do perfil Georadar 1 (Figura 4a) observa-se vários refletores, notáveis e de média continuidade lateral que podem ser individualizados e interpretados como estratificações cruzadas. A Figura 3 representa o perfil 1 de Georadar. Esta seção foi realizada paralela ao afloramento (figura 2) com 200 metros de extensão.

As estratificações cruzadas estão bem pronunciadas ao longo de todo 0 perfil, pois este se encontra paralelo às estratificações, que são destacadas na figura 4.b, a qual apresenta o radargrama interpretado. Essas estratificações são de portes decamétricos, localizada em toda extensão do perfil. Além das estratificações, é possível destacar uma possível grande falha entre as posições 170 a 200 metros.

A Figura 4a representa o perfil 2 de Georadar. Esta seção foi realizada paralela ao afloramento (figura 1) com 390 metros de extensão. Nesse radargrama do perfil Georadar 2 (Figura 5.a) observa-se vários refletores, notáveis e de continuidade lateral que podem ser individualizados e interpretados como estratificações cruzadas e dobras. No radargrama interpretado, (figura 5.b) têm-se além de estratificações cruzadas ao longo de todo o perfil, dobras suaves de grandes dimensões localizadas preferencialmente na região esquerda do radargrama. Além disso, é possível localizar um depósito recente entre as posições 190 a 290 metros e com profundidade de 5 metros. Na região entre as posições 350 a 380 metros é possível ver uma distorção do dados, isso se deveu a presença de um pequeno rio na região.

A Figura 5a representa o perfil 3 de Georadar. Esta seção foi realizada obliquamente ao afloramento (figura 1) com 420 metros de extensão. No radargrama do perfil Georadar 2 (Figura 6a) observa-se poucos refletores notáveis e com continuidade. No radargrama da figura 6.b. não é possível identificar estruturas tão evidenciadas como os radargramas das figuras 3 e 4 . Esse fato se deve as mudanças de direções da aquisição do perfil em relação à posição das estruturas a serem evidenciadas. O ângulo em que foi feita a aquisição não favoreceu um perfil claro e representativo das estruturas.

Com as observações dos perfis 1 e 2 de Georadar, conclui-se que o tipo litológico em subsuperfície pode ser correlacionado com o tipo litológico em superfície, que são quartzitos eólicos puros e finos da Formação Galho do Miguel, pois essa Formação é caracterizada por apresentar estruturas comoestratificações cruzadas de porte decamétricos, com presença de dobras e falhas em metassedimentos.

\section{Discussões e Conclusões (300)}

A caracterização de metassedimentos eólicos ainda é uma área inexplorada pelo método geofísico Georadar. Desse modo, a pesquisa com esse método conduzida na área de estudo representa um primeiro passo para a melhor caracterização litológica desse tipo de formação na região de Diamantina em Minas Gerais. A análise de 1.010 metros de seções de radar em Guinda forneceu uma caracterização precisa para a Formação Galho do Miguel em subsuperfície e essa conclusão é determinada através de interpretações de estruturas realizadas em radargramas mencionadas anteriormente.

Os dois primeiros perfis evidenciaram muito bem as estruturas por ser paralelos à direção longitudinal dessas. Estes realçaram as estratificações cruzadas e acanaladas de porte decamétricos, as falhas e as dobras no metassedimento. Já o terceiro perfil, mostrou discretamente as estruturas e isso se deveu a sua obliquidade em relação à direção longitudinal das estruturas na Formação Galho do Miguel

\section{Referências}

Annan, A.P. 1992. Ground penetration radar workshop notes. Sensors \& Software, Inc., Internal Report, 130 pp. 
Aranha, Paulo Roberto Antunes; Pena, Rodrigo Macedo; Knauer, Luiz Guilherme. Mapeamento Geológico da Região de Gouveia/MG com Auxílio de Métodos Geofísicos. Revista Geonomos, [S.I.], fev. 2013. ISSN 24466964.

Castro, David Lopes de et al. Ground-Penetrating Radar Imaging Techniques Applied In 3d Environment: Example In Inactive Dunes. Revista Brasileira de Geofísica, [S.I.], v. 32, n. 2, p. 273-289, fev. 2015. ISSN 1809-4511.

CPRM/PROSPEC/DNPM, 1974, Projetos Bahia, Bahia II, Sul da Bahia, Leste do Tocantins Oeste do Rio São Francisco. Salvador, relatório da reunião, 1974. 17 p.

Dossin,I.A.; Garcia,A.J.V.; Uhlein,A. \& Dossin,T.M. 1987. Facies eólico na Formação Galho do Miguel, Supergrupo Espinhaço-MG. Simp. Sist. Dep. Pré-Cambriano, Anais, pp. 85-96, Ouro Preto.

Knauer, Luiz Guilherme. O Supergrupo Eepinhaço Em Minas Gerais: Considerações Sobre Sua Estratigrafia e Seu Arranjo Estrutural. Revista Geonomos, [S.I.], fev. 2013. ISSN 24466964.

Rocha ,T.B.; Fernandez,G.B; Peixoto,M.N.O; Rodrigues,A. 2013. Arquitetura deposicional e datação absoluta das cristas de praia pleistocênicas no complexo deltaico do Paraíba do Sul (RJ). Brazilian Jornal of Geology, v. 43, n. 4 (2013) 
Anexo

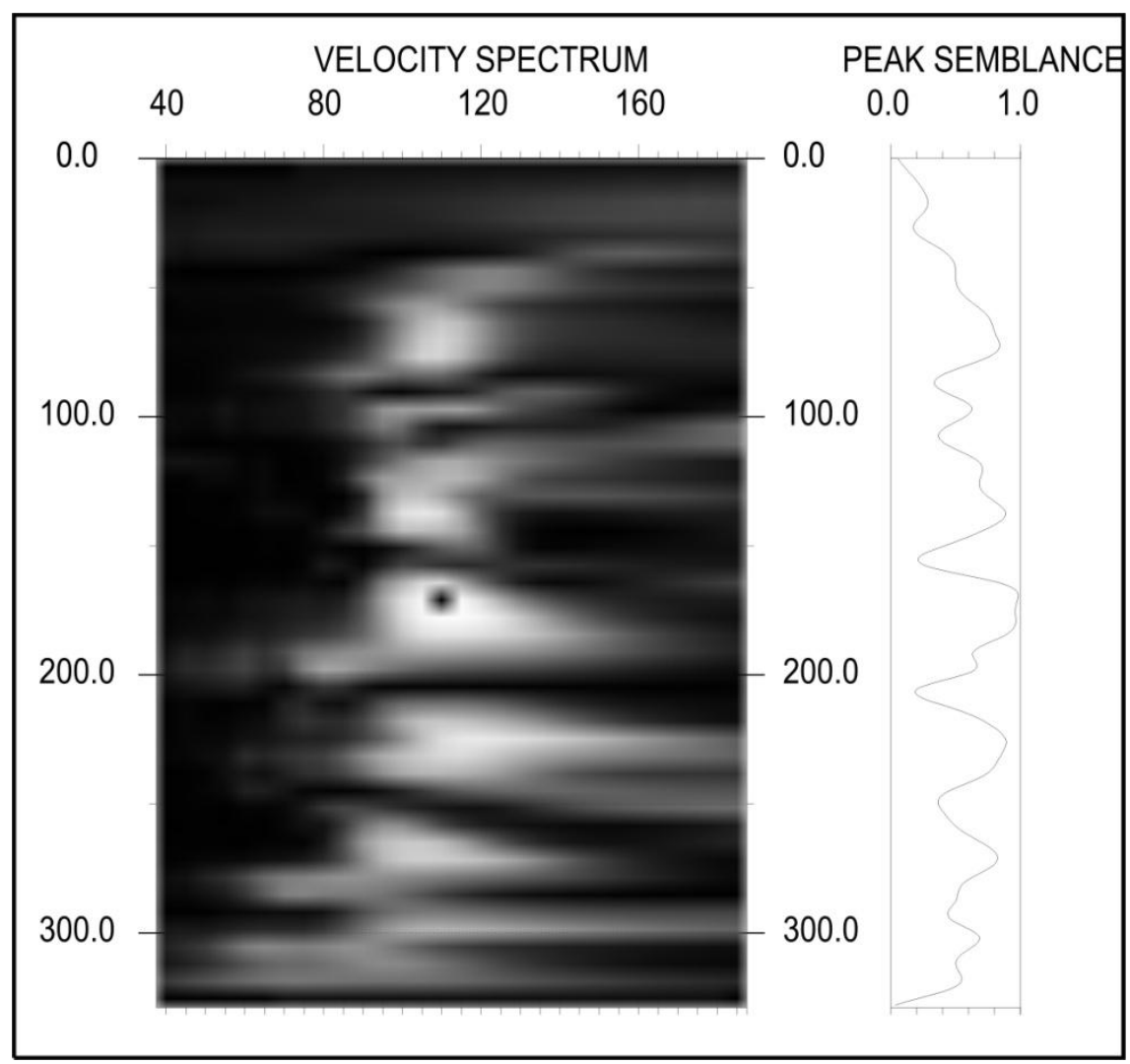

Figura 3 - Perfil de velocidade (CMP) adquirido na linha de perfil 1.

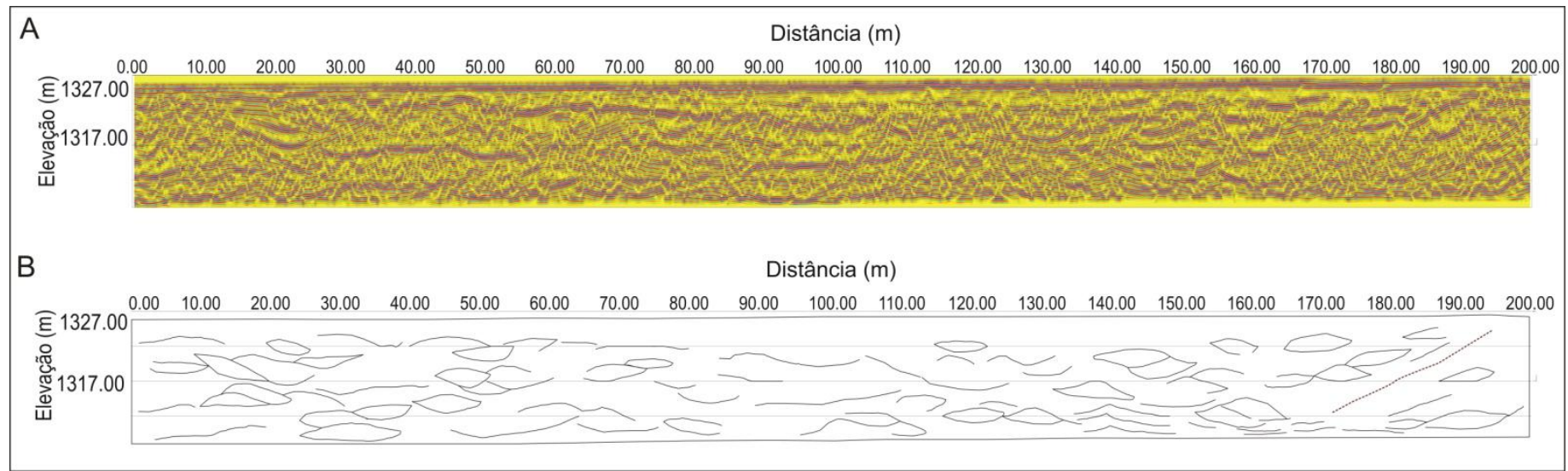

Figura 4 - a) Radargrama do perfil 1 em Georadar. b) Radargrama interpretado do perfil 1 em Georad 


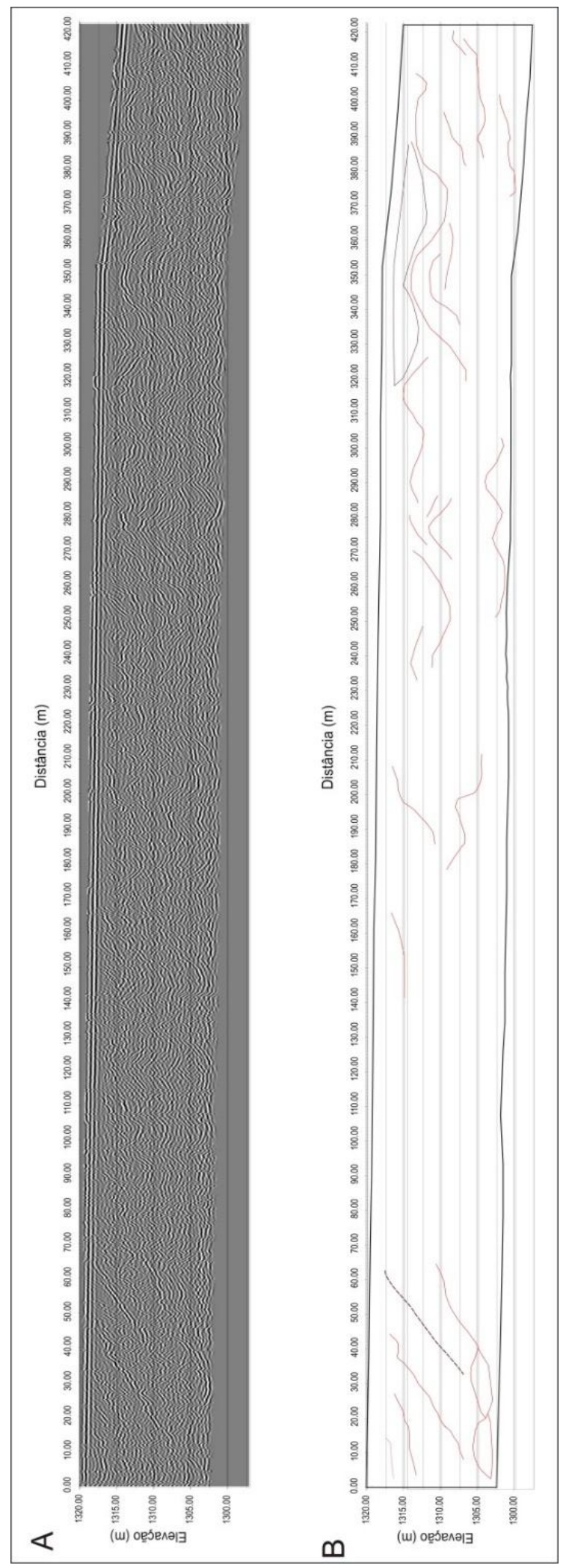

Figura 5 - a) Radargrama do perfil 2 em Georadar. b) Radargrama interpretado do perfil 2 em Georadar.

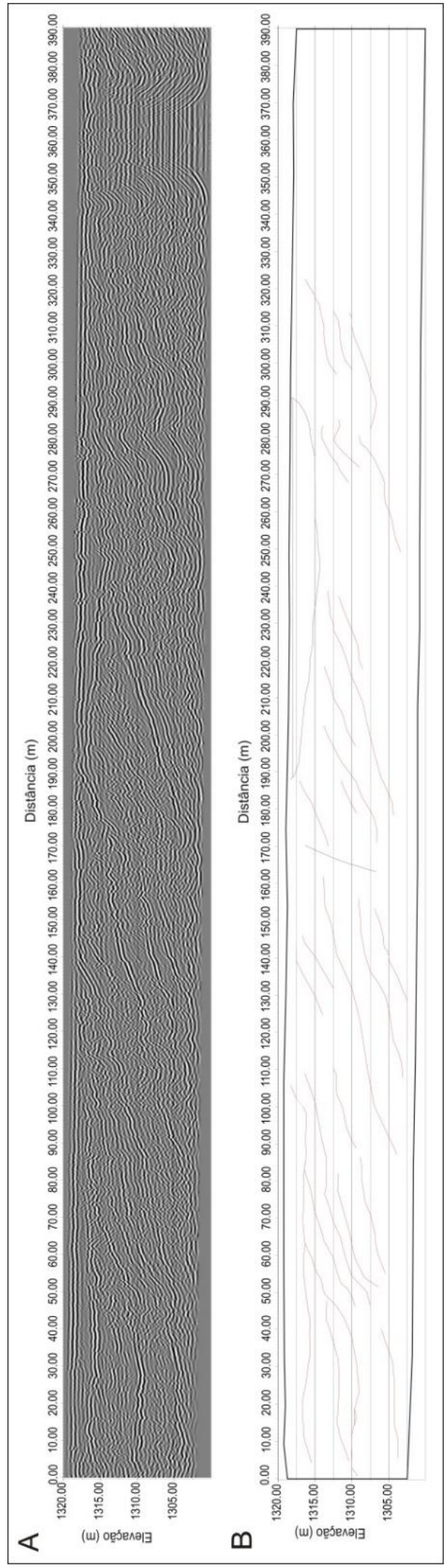

Figura 6 - a) Radargrama do perfil 3 em Georadar. b) Radargrama interpretado do perfil 3 em Georad 